\title{
Indoor Shooting Range Ventilation Systems ${ }^{\dagger}$
}

\author{
Alexandru Savastre \\ Research Center for Navy, 4 Stefanita Voda Street, 900402 Constanta, Romania; \\ savastrealexandru@gmail.com \\ + Presented at the 15th International Symposium "Priorities of Chemistry for a Sustainable Development" \\ PRIOCHEM, Bucharest, Romania, 30 October-1 November 2019.
}

Published: 12 October 2019

Keywords: shooting range; ventilation; $9 \times 19 \mathrm{~mm}$ cartridge; toxic fumes

It is understood that bullets are dangerous, assuming that they are fired into a body at high velocity. However, there are other ways in which a bullet can cause harm, such as through the emission of toxic fumes and metals. Performing experimental shooting with $9 \times 19 \mathrm{~mm}$ caliber weapons systems leads to certain reaction products being generated in quantities that can exceed the exposure limits of the human body. Carbon monoxide $(\mathrm{CO})$ and ammonia $\left(\mathrm{NH}_{3}\right)$ are typical components of the fumes that result during shooting. These gases, in addition to smoke particles, can cause symptoms such as nausea, headache, and coughing. Exposure to high concentrations of CO over time can ultimately lead to unconsciousness and death.

Experimental measurements were made for $109 \times 19 \mathrm{~mm}$ caliber cartridges. Under special training conditions, in $1 \mathrm{~h}$, more than 1000 fired cartridges can be produced. In order to keep the indoor air quality at an acceptable level, recirculation of the airflow must be prevented, so the ventilation or air conditioning system's air should be taken from the outside. The minimum fresh airflow is calculated to satisfy the following conditions: the dilution of harmful substances and the maintaining of healthy conditions.

For a given number of fired cartridges, the volumetric mass of the substances with harmful potential obtained is $4.69 \mathrm{~g} / \mathrm{m}^{3}$, as detailed in Figure 1, while the total occupied volume is $3.68 \mathrm{~m}^{3}$, at standard atmospheric conditions, as shown in Figure 2. In order to dilute these toxic reaction products, the minimum fresh airflow calculated is $891.6704 \mathrm{~m}^{3} / \mathrm{h}$. Also, the minimum fresh airflow needed to maintain safe conditions is $375 \mathrm{~m}^{3} / \mathrm{h}$.

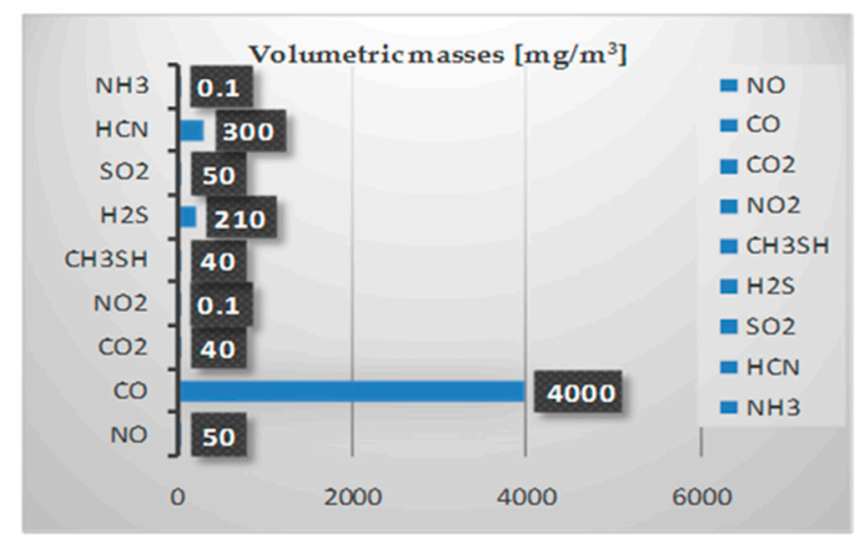

Figure 1. Percentage of substances with harmful potential. 


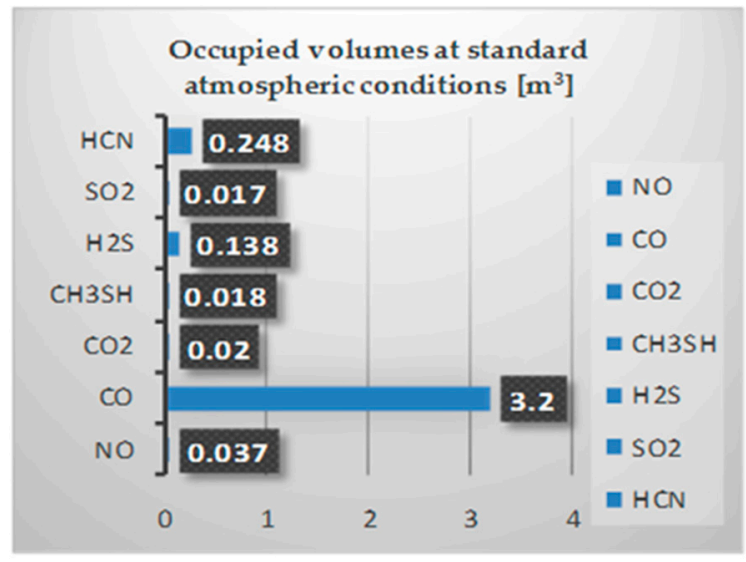

Figure 2. Occupied volumes at standard atmospheric conditions.

In order to prevent health risks due to the emissions of fumes from the use of weapons and ammunition, adequate ventilation and the use of protective measures are mandatory.

Acknowledgments: The author acknowledges the Romanian National Authority for Scientific Research (UEFISCDI) for the financial support, grant number PN-III-P1-1.2-PCCDI no.70/2018.

\section{References}

1. Johnsen, I.V., Johnsen, A.; Voie, Ø.A. Emission of toxic fumes and metals from weapons and ammunition. Presented at the European Conference of Defence and the Environment, Helsinki, Finland, 9-10 June 2015.

2. Vedinaş, I.; Şomoiag, P.; Surdu, G.; Mihuț, V. Considerations concerning the gasodymanic dispositives for the infantry weapons. Presented at the 32nd International scientific conference of the Military Technical Academy-Modern Technologies in the 21st Century, Bucharest, Romania, 1-2 November 2007; pp. 12001205, ISBN 978-973-640-127-5.

(C) 2019 by the authors. Licensee MDPI, Basel, Switzerland. This article is an open access article distributed under the terms and conditions of the Creative Commons Attribution (CC BY) license (http://creativecommons.org/licenses/by/4.0/). 